\title{
A Study of the Difference in Psychological Well-being of Male and Female Employees Working in Government and Private Sectors Exhibiting Three Levels of Organizational Role Stress
}

\author{
Dr Neeti Bisht ${ }^{1 *}$, Dr Sangeeta Khullar ${ }^{2}$
}

\section{ABSTRACT}

A study of difference in Psychological Wellbeing of 396 male and female employees working in government and private sector exhibiting three levels of organizational role stress was conducted(N= 198 each, age group 25-45 years). The tools used were Udai Pareek's Organizational Role Stress Scale (1986) and a self prepared questionnaire for measuring Psychological Wellbeing of the employees. The data was collected from the employees of well known private companies and government organizations such as Infosys, Reliance Telecommunications, Oil and Natural Gas Commission, State Bank of India etc. Three way ANOVA for Organizational Role Stress and Psychological Wellbeing of male and female employees working in the two sectors shows a significant main effect for the two sectors and the three levels of ORS but not for the two genders.

Keywords: Organizational role stress, Psychological Wellbeing, private sector, government sector.

The concept of stress was firstly introduced by Hans Selye in Life Science in the year 1936. According to him stress is "the force, pressure, or strain exerted upon a material object or person which resist these forces and attempt to maintain its original state." Stress is ubiquitous in today's world. It has become an integral part of everyday living. Stress is an unavoidable consequence of modern living. Growth of industries, pressure in the urban areas, quantitative growth in population and various problems in day to day life are some of the reasons for increase in stress. Stress is a condition of strain that has a direct bearing on emotions, thought process and physical conditions of a person. Stress in the workforce can burden companies with major problems: management and work productivity can be seriously impaired, motivation levels may

\footnotetext{
${ }^{1}$ PGT Psychology, Maxfort School Dwarka, New Delhi, India

${ }^{2}$ Associate Professor, M. K. P P.G College, Dehradun, India

*Responding Author

(C) 2016 N Bisht, S Khullar; licensee IJIP. This is an Open Access Research distributed under the terms of the Creative Commons Attribution License (http://creativecommons.org/licenses/by/2.0), which permits unrestricted use, distribution, and reproduction in any Medium, provided the original work is properly cited.
} 


\section{A Study of the Difference in Psychological Well-being of Male and Female Employees Working in Government and Private Sectors Exhibiting Three Levels of Organizational Role Stress}

be damaged and conflict between colleagues can undermine professionalism. With any of these factors in play companies will see damage to bottom line commercial and financial results. At a time when firms are fighting to return to a significant growth rate it becomes crucial to manage stress. In the health sector, where females face stressful situations due to irregular and long working hours, role pressure and work overload, they may become nervous and anxious Tsaur and Tang, (2012).

During the past decade, the corporate sector has under gone rapid and striking changes like, policy changes due to globalization and liberalization, increased competition due to the entrance of more private corporates, downsizing, introduction of new technologies, etc. Due to these changes, the employees in the corporate sector are experiencing a high level of stress.

With the introduction of new technologies, especially the extensive use of computers in all the sectors has changed the work pattern of the employees and has made it inevitable to downsize the work force in the sector. The implications of the above said transformations have affected the social, economic and psychological domains of the employees and their relations. All the factors discussed above are prospective attributes that cause occupational stress and related disorders among the employees. Role stress refers to the conflict and tension due to roles being enacted by a person at any given point of time. Pareek(2003).

Role is defined as a set of functions, which an individual performs in response to the expectations of others as well as his own expectations (Khan et al., 1964). The stress caused by the occupation of an organizational role-depends on an individual's perception about situations, constraints, opportunities or threats encountered during role performance. Stress is experienced when an individual encounters an opportunity, constraint, demand or threat, provided the outcome of the episode is both important and uncertain (Robbins, 2003, p. 577). Stress may involve: (i) not being able to do/get what one likes to do/get, (ii) losing something which someone likes to possess, (iii) an opportunity linked to a potential gain, (iv) threat of an impending punishment/failure/other negative consequences. Stress is a dynamic phenomenon dependent on individual perceptions and reactions. It is individualistic and additive. What may be highly stressful for one individual may not be stressful for others. What may be stressful for an individual under certain conditions may not be stressful for him under some other conditions. Stress at home gets added to stress in office and vice-versa. Stress is inevitable and cannot be avoided in our daily life (Pestonjee, 1999, pp. 15-34). Role (Pareek, 1993) refers to the position one occupies in a social system (or organization), as defined by the expectations of significant persons. The role occupant performs various functions in the organization to meet the expectations raised by the significant people in the organization with whom he has to interact, for the success of his role performance. An organization is a system of roles and role itself is a system. Organizational roles constitute the basic HR infrastructure on which the success of HR 


\section{A Study of the Difference in Psychological Well-being of Male and Female Employees Working in Government and Private Sectors Exhibiting Three Levels of Organizational Role Stress}

systems and processes depend (Srivastav, 2005). Membership of an organization and the concept of an organizational role have in-built potential for stress. Stress due to occupation of a role in an organization is known as Organizational Role Stress (ORS). The inverse causal relationship between role stress and performance, where performance is an antecedent to role stress, is also proposed and studied. Oliver and Brief (1977) found empirical support for performance as an antecedent to role ambiguity, discussed as performance feedback. Shirom and Kirmeyer (1988) found evidence that performance was both an antecedent and a consequence to role conflict, role ambiguity, and role overload, giving further cause for modeling a feedback relationship between performance and role stress. Other researchers have established that different performance indicators influence the dimensions of role stress. That is, job or venture performance as an antecedent is negatively related to role stress. Evidence in the literature supports this relationship. For instance, client satisfaction, as a component of venture performance, has been found to be negatively related to role stress Beard, (1999).

Organizational Role Stress/Conflict: Pareek (1976) classifies role conflict or role stress in two categories based on the concepts of role space and role set. He identifies five major role conflicts or stresses in the role space of an individual: Self-role distance, (2) Intra role conflict, (3) Role stagnation, (4) Inter-role distance (5) Role boundedness. Likewise he suggests five major conflicts or stresses in the role set: (1) Role stagnation, (2) Role erosion, (3) Role inadequacy, (4) Role ambiguity, (5) Role overload The concept of wellbeing originated from positive psychology. The shift from negative to positive psychology is a welcome change in discipline. Popular use of the term 'well-being' usually relates to health. Well-being is a kind of value, sometimes called prudential value', to be distinguished from, for example, aesthetic value or moral value. What marks it out is the notion of 'good for'.

Psychological Well-being is a subjective term that means different things to different people. Psychological Wellbeing refers to how people evaluate their lives. These evaluations may be in the form of cognition or in the form of affect. The assumption behind this is that most people internally evaluate their life as either good or bad enabling them to communicate their judgments.

Carl Ryff (1989) defined psychological well-being as self-acceptance, autonomy, environmental, mastery, purpose in life, positive relation with others and personal growth.

Self Acceptance: Positive attitude towards oneself; accepting of varied aspects of self; feel positive about past life.

Personal Growth: Feeling of continued development and effectiveness; open to new experiences and challenges. 
A Study of the Difference in Psychological Well-being of Male and Female Employees Working in Government and Private Sectors Exhibiting Three Levels of Organizational Role Stress

Purpose in Life: Possessing goals and beliefs that give direction to life; feeling life has meaning and purpose.

Environmental Mastery: Feel competent and able to manage a complex environment; able to create personally suitable living situations.

Autonomy: Feel comfortable with self-direction; possess internal standards; resists negative social pressures from others.

Psychological Well-being has been defined in terms of the internal experience of the employees and perception of their own lives. Some of the factors that may lead to employees' Psychological Well-being are: Feeling of accomplishment, feeling of using one's abilities to the fullest, recognition of work by superior, recognition of work by peer, promotion opportunities, pay. The concepts of psychological wellbeing in the present research apply a social-psychological perspective to the study of mental health among employees. Psychological Well-being gained its importance in last few years. Now more importance is given to psychological or mental wellbeing in comparison to physical health or wellbeing as it is considered to be the core aspect of an individual's overall wellbeing. Hence it is of significant importance for every organization to keep a check on their employees' psychological wellbeing as it will add to their performance and achievements. The psychological wellbeing of an employee can get affected negatively irrespective of the types of organization they are working in and the gender they possess. Psychological Well-being of an employee gets disrupted when the pressure at the workplace becomes difficult to cope with and possess a greater challenge in front of an employee which adversely affects their performance and the organizational productivity which is detrimental for any country's growth. Hence this makes it a necessity to do in depth analysis of the problem and its solution, which the present study aims at.

\section{METHOD}

\section{Participants:}

The total number of participants in the study was 396 male and female employees, 198 each from different government and private sector companies. The private sector companies included were HCL Info systems, Infosys Reliance Communications, NIIT Technologies, HDFC Bank and TV Today Network. Those from the government sector were ONGC, Indian Council for Forestry Research and Education, the Indian Army, State Bank of India and Hindustan Insecticide. Since the proportion of women employees is much lower than male employees in both the sectors, the numbers of women respondents from the government sector companies are 78 and those from the private sector are 62. 
A Study of the Difference in Psychological Well-being of Male and Female Employees Working in Government and Private Sectors Exhibiting Three Levels of Organizational Role Stress

\section{Measures:}

In order to assess Role Stress Pareek's Organizational Role Stress Scale was used which consists of 25 items. The factors included in the scale are-role stagnation, role erosion conflict, resource inadequacy, role overload, self-role distance. For measuring Psychological Well-being a self prepared questionnaire was used which consists of 15 items. The factors included in the questionnaire are: environmental mastery, autonomy, personal factors, positive relations with others and purpose in life.

\section{RESULTS}

Table 1: Compares Mean, SD and SE scores of male and female employees in government and private sector exhibiting three different levels of organizational role stress.

\begin{tabular}{|c|c|c|c|c|c|c|c|c|c|}
\hline \multirow{2}{*}{\multicolumn{2}{|c|}{ VARIABLES }} & \multicolumn{8}{|c|}{ SEX } \\
\hline & & \multicolumn{4}{|c|}{ MALE } & \multicolumn{4}{|c|}{ FEMALE } \\
\hline \multirow{2}{*}{$\begin{array}{l}\text { Dependent } \\
\text { Variable }\end{array}$} & \multirow{2}{*}{$\begin{array}{l}\text { Levels of } \\
\text { Dependent } \\
\text { Variable } \\
\text { (ORS) }\end{array}$} & \multicolumn{2}{|c|}{ Government } & \multicolumn{2}{|c|}{ Private } & \multicolumn{2}{|c|}{ Government } & \multicolumn{2}{|c|}{ Private } \\
\hline & & $\mathrm{M}$ & SD & $\mathrm{M}$ & SD & M & SD & $\mathrm{M}$ & SD \\
\hline \multirow{3}{*}{$\begin{array}{l}\text { Psychological } \\
\text { Well-being }\end{array}$} & LOW & 39.64 & 4.692 & 38.60 & 5.317 & 40.17 & 4.768 & 37.90 & 4.012 \\
\hline & MEDIUM & 38.59 & 4.643 & 36.59 & 5.123 & 38.93 & 4.238 & 37.10 & 3.315 \\
\hline & HIGH & 36.75 & 2.315 & 34.29 & 6.520 & 35.33 & 2.082 & 32 & 6.671 \\
\hline
\end{tabular}

Table-2: Summary of 2x2x3 ANOVA (Sector, Sex, ORS levels) of Psychological Well-being

\begin{tabular}{|l|l|l|l|l|l|}
\hline Source & Sum of Squares & df & $\begin{array}{l}\text { Mean } \\
\text { Squares }\end{array}$ & F & Sig. \\
\hline Sector & 182.016 & 1 & 182.016 & 7.695 & 0.006 \\
\hline Sex & 10.047 & 1 & 10.047 & 0.425 & 0.515 \\
\hline ORS levels & 382.182 & 2 & 191.091 & 8.079 & 0.000 \\
\hline Sector*Sex & 4.058 & 1 & 4.058 & 0.172 & 0.679 \\
\hline Sector*ORS levels & 7.667 & 2 & 3.833 & 0.162 & 0.850 \\
\hline Sex*ORS levels & 33.993 & 2 & 16.996 & 0.719 & 0.488 \\
\hline Sector*Sex*ORS levels & 6.431 & 2 & 3.215 & 0.136 & 0.873 \\
\hline Error & $9,083.020$ & 384 & 23.654 & - & - \\
\hline & & & & & \\
\hline Total & $566,304.000$ & - & - & & - \\
\hline
\end{tabular}

(c) The International Journal of Indian Psychology, ISSN 2348-5396 (e)| ISSN: 2349-3429 (p) | 141 


\section{A Study of the Difference in Psychological Well-being of Male and Female Employees Working in Government and Private Sectors Exhibiting Three Levels of Organizational Role Stress}

\section{DESCRIPTION}

The table above shows 2x3x3 ANOVA (sector, sex, Organizational Role Stress levels) of Psychological Well-being of employees. The sector as a main effect is significant $(\mathrm{F}=7.695$, $\mathrm{df}=1, \mathrm{P}=0.006)$. Organizational Role Stress levels as a main effect is also significant $(\mathrm{F}=8.079$, $\mathrm{f}=2, \mathrm{P}<0.000$ ). Sex as a main effect and all the interactions are not significant. There is $a$ significant difference in Psychological Well-being of employees working in government and private sectors._The result obtained from the study depicts that there is a significant difference between Psychological Well-being of government sector and private sector employees. The reason of this finding could be that the Psychological Well-being of employees is directly proportional to the type of organization and the culture of it. There is a striking difference in the climate of government sector and private sector organizations with respect to their culture and expectations from the employees. The result has been supported by the study of Alam, S.\& Rizvi, K (2012) who reported that Psychological Well-being among bank employees is higher in public sector as compared to their counterparts in private sector banks. Similar findings have been obtained by L. Nahar et. al. (2013) who found that the mental health of Government employees is slightly better than non-government employees. According to Clark (2006), Aittomaki, Lahelma and Ross (2003), Gillen Baltz Gassel, Kirsch and Vaccaro (2002), Demse, Erickson, Delbos and Banks (2005), there are multiple factors that can affect physical health and Psychological Well-being of workers. Research indicates that job strain or repetitive and hazardous work conditions may have detrimental effects on physical health. Stress experienced and perceived can affect a person's psychological wellbeing. Work stress research has examined the psychological demands of work load, worker's perceived sense of control over their performance, safety stressor, work organization and work atmosphere. An inconducive work environment can prove to be destructive and can generate a wide range of problems be it related to mind or body. Whereas having a good work environment proves to be an asset for the employees’ overall mental health.

Organizational role stress levels as a main effect is also significant $(\mathrm{F}=8.079, \mathrm{f}=2, \mathrm{P}<0.000)$. There is a difference in the Psychological Well-being of employees experiencing three levels of Organizational Role Stress. The varying amount of role stress has different impact on the mind of employees. As the amount of stress increases from low to medium and then high it greatly affects the wellbeing. As the role stress increases their Psychological Well-being lowers. According to Danna and Griffin (1999) some factors, like organizational stress, have an influence on employee well-being and health. Marzuki and Ishak (2011) also concluded that occupational stress at work and individual well-being appears to be closely intertwined. Based on the findings, they further stated that work stress dimensions, namely, role ambiguity and role conflicts correlated and influenced wellness. Jasmani binti Mohd Yunus and Abdul Jumaat bin Mahajar(2011) conducted a research on occupational stress among administrative and diplomatic officers in Malaysia and found that the occupational stress has significant positive 


\section{A Study of the Difference in Psychological Well-being of Male and Female Employees Working in Government and Private Sectors Exhibiting Three Levels of Organizational Role Stress}

correlation with psychological wellbeing. Thus it can be concluded that irrespective of the type of sector in which the employee is working, if the stress at the workplace increases the wellbeing tends to go down.

The result also show that gender as a main effect is not significant $(\mathrm{F}=0.425, \mathrm{f}=1, \mathrm{P}<0.515)$. There is no significant difference in Psychological Well-being of male and female employees under three levels of Organizational Role Stress. Creed and Macintyre (2001) also found no differences between males and females in Psychological Well being. The reason of this finding could be that today men and women both are working and are part of the same work culture and also there is an increasing trend of sharing responsibilities at home. The availability of resources and conveniences has made lives more comfortable especially for women which have enhanced their Psychological Wellbeing, bringing it at par with men. Where good organizational climate benefits both employees, in the same way poor organizational climate impairs functioning of both of them. The impact of stress therefore, on their life is also similar thus when they experience role stress in the organization their mental wellbeing gets affected in the same way.

The results from the present research show that role stress among private sector employees is more than government sector which is definitely affecting their wellbeing as a whole. The changing trend of the organizations in the competitive world of today and the thirst of maximizing profit is posing a greater demand on employees to perform more flexibly multiple and more complex roles within the organization. This has put employees in intricacy resulting in role stress among them, which is disrupting the employees' happiness and overall well-being. On one hand they are losing out on their professional front while on other they are also not able to fulfill their responsibilities at home properly and find it difficult to maintain the work life balance. Hence, there is an urgent need to formulate and implement upon the employee friendly policies to help them in developing a good mental health which inturn will enhance the productivity of the workforce and organizations at large. In the present study the data was collected from a small sample; hence the results may vary in a bigger or different sample. Thus it needs to be studied further so that these limitations can be addressed.

\section{Acknowledgments}

The author appreciates all those who participated in the study and helped to facilitate the research process.

\section{Conflict of Interests}

The author declared no conflict of interests.

\section{REFRENCES}

Alam, S. and Rizvi, K. (2012) Psychological Well-Being among Bank Employees. Journal of the Indian Academy of Applied Psychology, 38, 242-247. 


\section{A Study of the Difference in Psychological Well-being of Male and Female Employees Working in Government and Private Sectors Exhibiting Three Levels of Organizational Role Stress}

Beehr, T.A.\& Newman, J.E. (1978). "Job Stress, employ Health and Organizational Effectiveness- A fact analysis model and literature reviews." Personal Psychology”, 31, pp.665-669.

Bhatia, P., and Kumar, A. (2003), "Occupational Stress and Burnout".

Bhattacharjee, A (2013), "Who Feels Happier? A Study On Government And Private Sector Employees Of Tripura".

Burke, R. J. (2002). Organizational values, job experiences and satisfaction among managerial and professional women and men: Advantage men? Women in Management Review 17 (5): 5-6.

Chekola, M.G. (1975). The concept of happiness. University of Michigan. Dissertation Abstracts International, 35, 4609A.

Creed, P. A., \& Macintyre, S. R. (2001). The relat ive effects of deprivation of the latent and manifest benefits of employment on the wellbeing of unemployed people. Journal of Occupational Health Psychology, 6(4), 324-331.

Culberson, C.E. (1977). Aholistic view of joy in relation to psychotherapy derived from Lowen, Maslow, and Assagoli. Dissertation Abstracts International, 38, 2853B.

Danna, K., \& Griffin, R. W. (1999). Health and well-being in the workplace: a review and synthesis of the literature. Journal of Management, 25, 357-384.

Diener, Ed., Suh, E., \& Oishi, S. (1997). Recent findings on subjective well being. Indian Journal of Clinical Psychology.

Emslie C, Hunt K, Macintyre S.(2004);Gender, work-home conflict, and morbidity amongst white-collar bank employees in the United Kingdom, 11(3):127-34.

Farooque A. Shah (2003), "Role Sress in Indian Industry: A Study of Banking Organisations, "Indian Journal of Industrial Relations, Vol. 38, No.3, Jan.

Hochschild, A.R. (1997). The time bind: When work becomes home and home becomes work. New York: Metropolitan Books.

Indian Psychological Review, Vol. 60, pp. 145-153

Jahoda, M. (1958). Current concepts of positive mental health. NewYork: Basic Books.

Jasmani Binti Mohd Yunus and Abdul Jumaat bin Mahajar(2011). The Journal of Human Resource and Adult Learning Vol. 7, Num. 2.

Jick TD, Mitz LF. (1985). Sex differences in work stress. Academic Management Review.

Kanter, R. M. (1977). Work and family in the United States: A critical review and agenda for research and policy. New York: Russell Sage Foundation.

Katz, D., \& Kahn, R. L. (1966). The social psychology of organizations. New York: John Wiley and Sons.

Khatri, N., \& Budhwar, P.S. (2000). A study of strategic HR issues in an Asian context. Personnel Review, 21(1/2), 166-168.

L. Nahar et al. (2013), A investigated relationship of job satisfaction, job stress and mental health on government and non-government employees . Psychology 2013. Vol.4, No.6, 520-525. 


\section{A Study of the Difference in Psychological Well-being of Male and Female Employees Working in Government and Private Sectors Exhibiting Three Levels of Organizational Role Stress}

Lambert, E. G. et al. (2007). The job is killing me: The impact of job characteristics on correctional staff job stress. Journal of Applied Psychology., 3 (2): 117-142

Marcinkus, W. C., K. S. Whelan-Beny, and J. R. Gordon. (2007). The relationship of social

Marzuki, N. A, \& Ishak, A. K. (2011). Towards healthy organization in correctional setting: correctional officers” wellness, occupational stress, and personality. International Journal of Social Sciences and Humanity Studies , 3 (2), 355-365.

Moorehead, Steele, Alexander, Stephen and Duffin (1997), Chnages at work: The 1995 Australian workplace and industrial relations survey. Melbourne: Longman.

Narayanan L, Menon S, Spector PE. (1999). Stress in the workplace: a comparison of gender and occupations. Journal of Organizational Behaviour.

Nirmala (2002). "Occupational Stress and Job Performance: A Study in Banking Industry", PlMR, Vol. 6, No. 1-2, April-October.

Pestonjee, D.M. and U.B. Singh. Job satisfaction as a function of role stress, locus of control, participation and organizational climate in an electric supply company, Ahmedabad, Indian Institute of Management, 1982.

Pestonjee, D.M. (1999). Stress and Coping: The Indian Experience, New York: Sage Publishers.

Sauter, S., Hurrell, J. Jr., Cooper, C. (Eds.) (1989). Job control and worker health. New York: Wiley.

Selye, H. (1974). "Stress without Distress." Harper and Row Publications, U.S.A.

Shah, F. A. 2003. Role stress in the Indian industry: A study of banking organizations. Indian Journal of Industrial Relations, Shriram Centre for Industrial Relations and Human Resources. 38(3): 281-296

Singh, S., (1990). Organizational Stress and Executive Behavior. Sreeram Centre for Industrial Relation and Human Resources, New Delhi.

Singh, B. (2004). Working women in India. New Delhi: Anmol.

Verma, S. K., Dubey, B.L., \& Gupta, D. (1983). PGI General Well-being Scale. Indian Journal of Clinical Psychology, 10, 299-304.

Wiersma, U., \& Berg, P. (1991). Work-home role conflict, family climate, and domestic responsibilities among men and women. Journal of Applied Social Psychology, 21, 12071217.

World Health Organization. (1998). The World Health Report, 1998. Executive summary. Geneva.

How to cite this article: N Bisht, S Khullar (2016), A Study of the Difference in Psychological Well-being of Male and Female Employees Working in Government and Private Sectors Exhibiting Three Levels of Organizational Role Stress, International Journal of Indian Psychology, Volume 3, Issue 4, No. 75, ISSN:2348-5396 (e), ISSN:2349-3429 (p), DIP:18.01.052/20160304, ISBN:978-1-365-50727-4 